Brit. J. vener. Dis. (1960), 36, 243.

\title{
TRANSPORTATION OF MATERIAL FOR THE CULTURE OF THE GONOCOCCUS*
}

\author{
BY \\ ALICE REYN, BENT KORNER, AND MICHAEL WEIS BENTZON \\ Statens Seruminstitut, Copenhagen, Denmark
}

Until the beginning of World War II the culture method was not extensively used in the diagnosis of gonorrhoea; diagnosis by culture was made only where laboratory facilities were available close to the clinics. The rapidly increasing incidence of gonorrhoea-especially among soldiers - made it desirable to obtain better diagnosis and control of the disease, and it became necessary to provide clinical diagnosis and treatment away from laboratory facilities, so that suitable transportation methods were needed. It was also desirable to diagnose and control chronic gonorrhoea in women more efficiently; microscopical diagnosis was difficult and much stood to be gained if culture methods could be used to a greater extent. The transportation of material to be tested for growth of gonococci has, however, presented greater problems than were encountered with many other pathogenic bacteria.

When the laboratories were in close connexion with the clinics, the infected material was inoculated immediately on plates in the clinic and transported as soon as possible to the laboratory, or else swabs were placed in small tubes or bottles (with or without a nutrient medium) and transported to the laboratory, preferably not more than a few hours later. In places without laboratory facilities it was usual to keep the temperature constant during transportation

\footnotetext{
* Received for publication May 11, 1960.
}

at body temperature, about zero, or below zero; but this involved costly special equipment such as thermos bottles.

During the war the transportation problems were studied, but the published papers dealt mainly with the superiority of the culture method over the microscopy method, especially in women. The choice of the most suitable media for transportation and culture was also discussed, and many procedures were tested.

In the present paper, however, only articles directly connected with the present investigation will be referred to.

\section{Factors affecting Survival and Growth of the Gonococcus}

Dessication and exposure to sunlight should be avoided during transportation and the viability of the gonococci is enhanced by increased $\mathrm{CO}_{2}$ tension and decreased $\mathrm{O}_{2}$-tension. Increased $\mathrm{CO}_{2}$ tension favours the growth (multiplication) of gonococci, but its significance for preservation during transportation is more questionable (McClure and Miller, 1946; Peizer and Steffen, 1947; Peizer, Steffen, and Klein, 1949; Schubert, Bucca, and Thayer, 1947; Buck, 1947; Hüllstrung, 1949). The addition of reducing substances to the transportation medium, such as thioglycollic acid (Stuart, 1946), 
ascorbic acid (LeMinor, LeMinor, and Combs, 1949), or cysteine (Barlow, Yamakawa, and Cavanaugh, 1955), has been recommended. The consistency of the transport medium and its nutritional properties, inhibitory and protective substances, $\mathrm{pH}$, and salts have also been considered (Hill, Nell, and Mueller, 1948; Mullaney, 1951). Survival during transportation is enhanced in media which support the growth of gonococci, provided that overgrowth of contaminants does not occur (Reymann, 1941, 1944).

The temperature and the time factor are most important. After an initial loss in viable count, both deep-frozen and freeze-dried gonococcus cultures keep very well (Reyn, 1947; Wortman, Gronau, Deakin, and Love, 1941; Stuart, 1946; Reymann, 1941; Deakin, 1942; Sanderson and Allison, 1942). At temperatures about zero the rate of decrease in the viable count is low for both the gonococci and the contaminants; with rising temperature the metabolic rate of the micro-organisms increases. Microorganisms able to multiply under the given nutritional conditions will survive and may increase, whereas others for which the conditions are less favourable will die. Many gonococcus strains have rather special nutritional requirements (Lankford, Scott, Cox, and Cooke, 1943; Lankford and Snell, 1943; Gould, Kane, and Mueller, 1944; Lankford and Skaggs, 1946), are susceptible to the presence of minimal amounts of inhibitors (Ley and Mueller, 1946) - such as fatty acids and impurities in the peptone (McLeod, 1947; Hill and others, 1948)and do not multiply under $30^{\circ} \mathrm{C}$. and over $41^{\circ} \mathrm{C}$. (Burrows, 1954). At temperatures from about $8-10^{\circ} \mathrm{C}$. and upwards, many of the contaminants will have a good chance of overgrowing the gonococci, especially if these latter are few.

Selective inhibition of the contaminants by antibiotics or dyes was tried by many authors (Peizer, 1942; Cox, McDermott, and Mueller, 1942; Peizer and Steffen, 1943; Cox and McDermott, 1943; Stokinger, Ackerman, and Carpenter, 1943; Sulkin and Willett, 1944; Hirschberg, 1945; Porterfield and Nelson, 1944; Peizer and others, 1949), the inhibitors being used either in the transport medium or in the culture medium or in both. However, concentrations were needed which are very close to those also inhibitory for the gonococci (Reymann, 1944; Lagergren and Ouchterlony, 1948; Reyn, 1951).

Overgrowth by contaminants can also be counteracted by spreading the infected material on plates or slants before transportation, or by use of a solid rather than a fluid medium for the transportation of swabs. Previously, fluid or semi-solid transportation media were most frequently used; however, Reymann (1941) described a transportation method in tubes with solid medium. The inoculated swabs were placed in slanted tubes containing about two $\mathrm{ml}$. McLeod's chocolate medium (McLeod, Coates, Happold, Priestley, and Wheatley, 1934; McLeod, 1947). The tubes were tightly closed with cottonwool plugs soaked with paraffin and the swab rested on the surface of the medium during transportation; a certain degree of moisture was secured and nutritional factors could diffuse from the slant into the swabs. With this method the loss was negligible for up to 12 hours at temperatures from about $-10^{\circ} \mathrm{C}$ to $25^{\circ} \mathrm{C}$. (Reymann, 1944). Between 12 and 24 hours there was a 40 per cent. loss, mainly due to overgrowth of contaminants; more overgrown plates were naturally found in the summer than in other seasons.

Peizer and Steffen (1943) found practically no loss when the infected material was inoculated on plates with plasma haemoglobin agar containing cysteine and transported for 20 to 24 hours at room temperature. However, this method is expensive and requires some bacteriological training of the clinical staffs.

Hirschberg (1945) used a method somewhat similar to that of Reymann. Infected swabs were inserted into 5-ml. solid medium (chocolate agar with Nile blue A), and the transportation loss was 40 per cent. after 2 to 4 days.

Stuart (1946) thought that the most logical way to counteract contamination would be to keep the metabolism at a low rate during transportation. He pointed out that desiccation is not in itself a process lethal to most bacteria; in fact freeze-drying in vacuo is a recognized method of preserving bacteria. The prevention of death by this procedure is due to the absence of oxygen as much as to the prevention of protein denaturation by rapid freezing (Rahn, 1945). A non-nutrient semi-solid medium in which oxidation would be prevented by a chemical reducing agent suggested itself to Stuart, especially since established gonococcus cultures show increased viability when maintained under anaerobic conditions. On the basis of results with pure cultures, Stuart built up a transportation medium consisting of 0.3 per cent. agar, 0.1 per cent. sodium thioglycollate, 1 per cent. sodium glycerophosphate, and 0.001 per cent. $\mathrm{CaCl}_{2}$; methylene blue was added as an indicator of the oxygen tension. The material was collected on cotton-wool swabs and the medium was dispensed in screw-capped bottles. No comparison was made between immediate plating and transported specimens, but it was found that gonococci from clinical material could maintain their viability for 15 days in this medium and fifty positive cultures were found out of 83 specimens 
which had been transported for 19 to 48 hours. Moffett, Young, and Stuart (1948) used Stuart's method and compared the results found by culture and by microscopy; the combination of smear and culture discovered 24 per cent. more positives than smear examination alone, and culture alone 10 per cent. more than smear. It was recommended to boil the swabs in Sørensen's phosphate buffer solution pH 7.4 and to impregnate the swabs with a 1 per cent. water suspension of finely-ground charcoal.

The methods of Reymann and Hirschberg were combined by Reyn $(1949,1951)$; infected cotton-wool swabs were dug into tubes containing 2 to $3 \mathrm{ml}$. McLeod's chocolate agar without the addition of any inhibiting substance.

In some preliminary experiments (Reyn, 1947b, unpublished) with pure gonococcus cultures, this method was compared with the Stuart and Reymann methods. After 24 hours' transportation the results were fairly equal with the three methods, but the Stuart method was slightly inferior to the others, especially when the agar percentage in the Stuart medium was increased for practical reasons.

LeMinor and others (1949) compared the results of transportation in the Stuart medium with those obtained by direct plating, the thioglycollate in the medium being replaced by ascorbic acid. Less than 20 per cent. positive cultures were lost after transportation for 2 days. Mülhens (1950) agreed with Stuart that a non-nutrient reducing transport medium was preferable, but he did not succeed with Stuart's medium, perhaps because of impurities in the particular batch of thioglycollate employed. The use of tubes containing a $10-\mathrm{cm}$. layer of 1.5 per cent. Danager, charcoal, and "Cebion" (ascorbic acid) was recommended. Wilkinson (1951) found that gonococci may keep for 25 to 52 hours in specimens transported in Stuart's medium, and Alexander (1952) got more positive cultures after transportation in Stuart's medium than by direct immediate culture. Alexander thought that the boiling of the wooden applicators was unnecessary if best quality wood and wool were used.

Mullaney (1951) composed a transportation medium from agar, albumin, phosphate buffer, and charcoal; 21 cultures from 26 patients were positive after transportation in this mediumm for 24 hours, and 21 positive cultures were also obtained in another series of 26 patients in which the Stuart method was used. Thus the two methods were not compared directly.

As already mentioned, the Stuart method was modified by the impregnation of the swabs with charcoal; Stuart, Toshach, and Patsula (1954) demonstrated in pure cultures that the inhibitory effect of "bad" agar could be prevented by using charcoal swabs instead of ordinary swabs. The percentage of positive cultures was compared for two periods, ordinary swabs being used in the first and charcoal swabs in the second; $5 \cdot 4$ per cent. positive cultures were obtained in the first period and $11 \cdot 2$ per cent. in the second. The difference was statistically significant and the comparison of the results from the two different periods was found to be justified by the fact that the percentage of specimens positive by microscopy was the same in the two periods.

Barlow and others (1955) modified the Stuart method by replacing thioglycollate and methylene blue with cysteine and resazurin. About 20 per cent. positive cultures were lost after transportation in this medium for 24 hours; it was thought that a low agar concentration was preferable.

Heidbreider, Laurence, Deboynton, and Lahr (1955) compared the Stuart method with the method of Peizer and others (1949); duplicate swabs were taken from fifty patients at "the same time", and one was transported in Stuart's medium and the other in Peizer's medium. 47 patients gave positive cultures; eleven specimens were positive with the Stuart method only, and one specimen was positive in the Peizer medium only.

Stuart (1956) reviewed his results from the years 1951 to 1955 . About twice as many positive results were obtained by his method than by microscopy, both used alone. From 24 hours' delay to 48 hours, delay the loss of positive cultures was only about 30 per cent. and positive results were frequently obtained after 96 hours' transportation.

Beakley (1957) found that some wooden applicators were toxic and that gonococci transported on them were killed very quickly; he therefore recommended the use of aluminium wire.

Colquhoun and Cooper (1957) used the Stuart method only in a 12 months' trial period and were very content with their results, especially in women.

Griffin and Rieder (1957) used a simplified agar medium for transportation and isolated the gonococci on hermetically sealed Petri dishes.

In December, 1957, Dr. O. Ringertz, visiting this institute, reported promising results obtained in Sweden with the Stuart method compared with the McLeod-Reymann method. Since July, 1958, a modification of the Stuart method had been used in the Statens Bakteriologiska Laboratorium, Stockholm, as the only method resulting in a significant increase in the percentage of positive female cultures in longdistance specimens (Ringertz, 1960). Quite recently Laurell (1959) reported from Lund, Sweden, the better survival of laboratory gonococcus strains in 
the Stuart medium as compared to those in the McLeod-Reymann medium. These observations, together with the above-mentioned increasing evidence in favour of the Stuart method, suggested a comparison of this method with the routine method of the Statens Seruminstitut, Copenhagen. The experiments were started in July, 1958. After the completion of our comparison, however, Stuart and his collaborators published a new series of papers in which the use of Polymyxin B sulphate in the culture medium was recommended (Crookes and Stuart, 1959; Stuart, 1959; Stuart and Crookes, 1959). Hence, our experiments were supplemented with a comparative study of culture medium with and without Polymyxin B sulphate.

\section{Present Study}

Transportation Media.-At first the Stuart medium was prepared exactly in accordance with the prescription (Stuart, 1946), and was dispensed in 10-ml. screw-cap bottles instead of the recommended slightly smaller "bijou" bottles. Later on the agar concentration was increased and the medium was dispensed in tubes closed with paraffinated cotton-wool plugs as indicated below.

The routine medium was composed as follows: $1,000 \mathrm{ml}$. ox or veal meat broth with about 2 per cent. agar (Japan agar, Kobe 1, selected) were melted and cooled to $80^{\circ} \mathrm{C}$; $100 \mathrm{ml}$. defibrinated horse blood was added and the mixture was kept at $80^{\circ} \mathrm{C}$. for 10 minutes under frequent shaking. Quantities corresponding to $1 \cdot 5-\mathrm{cm}$. high layers were poured into cotton-wool plugged tubes $(15 \times 150 \mathrm{~mm}$.) and the tubes were cooled in a vertical position. They were kept overnight in the refrigerator and next day the plugs were removed by a sterile pincet, dipped into sterile melted paraffin of a suitable consistency, and inserted into the tubes again. In fact, a "chocolate" medium was used as indicated by McLeod and others (1934) and the following routine method was referred to as the "McLeod Method".

Swabs.-Charcoal swabs were prepared as described by Moffett and others (1948). In addition, swabs were prepared with either hydrophobic or hydrophilic cotton wool; like the charcoal swabs they were boiled in phosphate buffer before use.

Culture Medium.-The broth agar base was made up of about 1.8 per cent. agar (Japan, Kobe 1) in beefheart broth with 1 per cent. peptone (Orthana), 0.3 per cent. $\mathrm{NaC1}$, and 0.2 per cent. $\mathrm{Na}_{2} \mathrm{H}, \mathrm{PO}_{4}, 12 \mathrm{H}_{2} \mathrm{O}$. The base was dispensed in 540-ml. amounts in Erlenmeyer flasks and kept in the refrigerator; before further preparation it was melted and heated to $80^{\circ} \mathrm{C}$., $60 \mathrm{ml}$. defibrinated horse blood was added, and the mixture was kept at $80^{\circ} \mathrm{C}$. for 15 minutes under frequent shaking. Then it was cooled to $56^{\circ} \mathrm{C}$. and mixed with $300 \mathrm{ml}$. sterile ascitic fluid, which was brought to $56^{\circ} \mathrm{C}$. before mixing and pouring into plates.
Diagnostic Criteria of Gonococci.-The organisms must be Gram-negative diplococci forming typical colonies on McLeod's medium enriched with ascitic fluid as described above. They must be oxidase-positive and must form acid on 1 per cent. glucose ascitic agar plates and no acid on 1 per cent. maltose ascitic agar plates.

\section{Experiments}

Artificial Specimens.-Preliminary experiments indicated that:

(1) Charcoal swabs when used in Stuart's medium were highly superior to the other swabs,

(2) The three types of swabs gave about equal results when used in McLeod tubes.

(3) The Stuart bottles preserved gonococcus cultures better than did the McLeod tubes.

Experiments with Pure Gonococcus Cultures.-18 hrs' growth from plates inoculated with 10 recently isolated pure gonococcus cultures was suspended in ordinary broth to a viable count of about $5 \times 10^{8}$ per $\mathrm{ml}$. The densities of the suspensions were determined visually and controlled by counting on plates after serial dilution. The 10 suspensions were diluted $1: 100$ in broth and $0.05 \mathrm{ml}$., was pipetted into each of a series of small sterile tubes; from these tubes all the fluid was removed by charcoal swabs. The swabs were inserted into either Stuart bottles or McLeod tubes. Half of the bottles and tubes were shaken to imitate the movements during transportation and half were not shaken; two swabs were used for each condition. For each strian 32 swabs were infected. Eight swabs were plated immediately afterwards (four from Stuart bottles and four from McLeod tubes) to serve as controls, $3 \times 8=24$ swabs were used for delayed plating after 24,48 , and $72 \mathrm{hrs}$. standing at room temperature $\left(23-25^{\circ} \mathrm{C}\right.$.).

The results were read after 48 hours (24 hours in $\mathrm{CO}_{2}$, 24 hours without $\mathrm{CO}_{2}$ ) and the degrees of growth were roughly estimated as: $0 \cdot 5,1,2,3$, and 4 degrees. No difference was observed between the cultures which had been shaken and those which had not been shaken; in the subsequent experiments shaking was omitted.

In Fig. 1 (opposite) the average degrees of growth for the Stuart and McLeod methods are plotted against each other for immediate platings and for platings delayed for 24, 48, and 72 hours. Growth was best after "transportation" in the Stuart medium and that it diminished with time for both methods. After 24 hrs' "transportation", all the cultures were positive, after $48 \mathrm{hrs}$ one culture was negative with each method, and after $72 \mathrm{hrs}$ six cultures were negative with the McLeod method and only one with the Stuart method.

Experiments with Contaminated Cultures.-Typical contaminants, isolated from the routine cultures were used: two strains of diphtheroids showing either green or yellowish haemolysis on the McLeod plates; two Staphylococcus albus strains, one of which showed a dark zone 


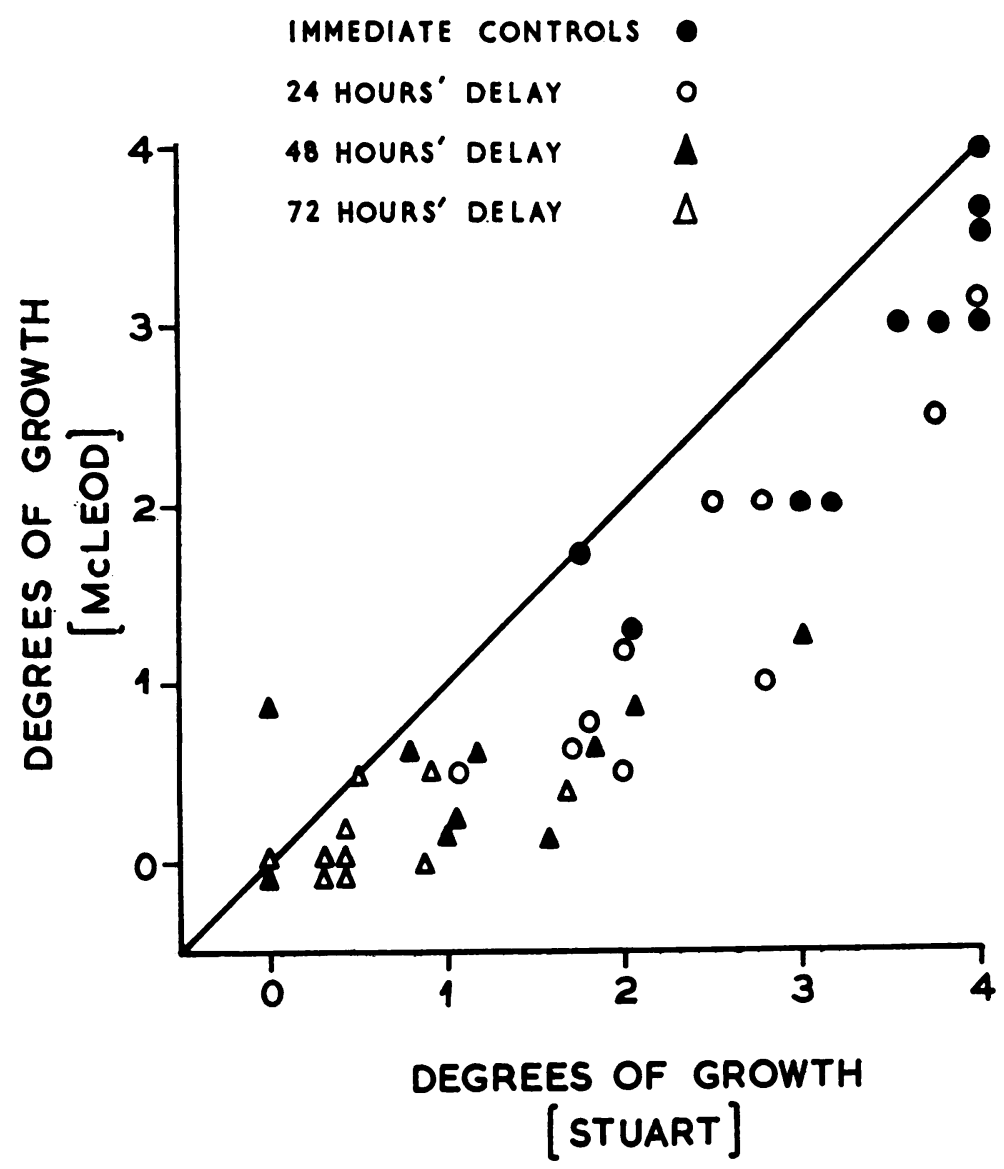

Fig. 1.-Average degrees of growth for ten artificial gonococcus specimens (10 different strains) transported in Stuart bottles and McLeod tubes.

around the colonies; one $E$. coli; one culture of Gramvariable cocci. In a preliminary experiment, it was found that the contaminants (when suspended to about the same density as the gonococci) should be diluted $0 \cdot 1: 100$ in broth to give a suitable growth; yet the diphtheroids, which grew less abundantly, should be diluted $0.5: 100$ only.

Suspensions were prepared of the contaminants and of a recently-isolated pure gonococcus strain. Swabs were infected with these suspensions and with mixtures of the gonococcus suspensions and aliquots of each of the other suspensions (two swabs per suspension). The infected swabs were "transported" for 24 and $48 \mathrm{hrs}$ at $4^{\circ} \mathrm{C}$., $25^{\circ} \mathrm{C}$., and $37^{\circ} \mathrm{C}$.; controls were plated immediately.

In spite of the results of preliminary experiments, it was found that the growth of the contaminants was too heavy, except for the diphtheroids. After 24 hrs' "transportation" at $4^{\circ} \mathrm{C}$. and $25^{\circ} \mathrm{C}$., the Stuart method preserved the gonococci in two of the six mixtures; in all the other mixtures no gonococci were left. When "transported" alone, the gonococci were well preserved with both methods and so were the contaminants. After $48 \mathrm{hrs}$, gonococci were found in four of the mixtures "transported" at $4{ }^{\circ} \mathrm{C}$., in Stuart bottles and in one of the mixtures kept at $37^{\circ} \mathrm{C}$. in McLeod tubes; in all the other mixtures no gonococci were cultured. All the pure gonococcus suspensions showed a maximum degree of growth.

A tendency to poor growth of the contaminants (alone and mixed) was seen with the Stuart method as compared with the McLeod method. For both methods the growth was richer after storage at $25^{\circ} \mathrm{C}$. and $37^{\circ} \mathrm{C}$., than aftcr 
storage at $4^{\circ} \mathrm{C}$. To confirm these findings another experiment was set up in which the same six contaminants were "transported" as described above, but with the suspensions (except the diphtheroids) diluted five-fold more than in the previous experiment. The degrees of growth were this time estimated as $0 \cdot 1,1,2, \ldots 6$.

The six contaminants responded similarly to the experimental conditions. In Fig. 2 the average degrees of growth for the six contaminants are plotted against time. The degree of growth for the six contaminants are plotted against time. The degree of growth was constant and low after 24 and $48 \mathrm{hrs}$ at $4^{\circ} \mathrm{C}$. for the McLeod method; at $25^{\circ} \mathrm{C}$. and $37^{\circ} \mathrm{C}$. the degree of growth was nearly maximal after 24 hours, and maximal after $48 \mathrm{hrs}$.

With the Stuart method the initial value was higher than with the McLeod method; after 24 hours at $4^{\circ} \mathrm{C}$., there was a drop followed by an insignificant slight rise after 48 hours. After 24 hours at $25^{\circ} \mathrm{C}$. and $37^{\circ} \mathrm{C}$., the growth was fairly constant as compared with the initial growth; after 48 hours there was a moderate rise.

Suspensions of $B$. proteus ( $\leqq$ one organism per $\mathrm{ml}$.) were "transported" in a similar experiment to that described above; the growth was equal by the two methods and only at $4^{\circ} \mathrm{C}$. were some of the plates not overgrown.

Consistency of the Medium.-The semi-fluid character of the Stuart medium is somewhat inconvenient; to avoid extra contamination the swabs should be broken in a sterile manner. The handling of the specimens at the laboratory is more laborious than when unbroken swabs can be used. Therefore, experiments were set up using increased agar concentrations.

(a) Ten recently isolated gonococcus strains were "transported" in Stuart bottles with $0 \cdot 3,0 \cdot 6,0 \cdot 9$, and $1 \cdot 2$ per cent. Bacto agar and in McLeod tubes. No significant differences in the degree of growth were found between the various concentrations. The inferiority of the McLeod method was confirmed.

(b) Bacto agar is more expensive than Japan agar, which is in general use in the Statens Seruminstitut. As a security against unsuitable batches, every new batch of agar is tested in a series of media before use. A selected Japan agar batch was compared with Bacto agar in an experiment using five gonococcus strains and three different agar concentrations: $0 \cdot 3,0 \cdot 7$, and $1 \cdot 2$ per cent. for Bacto agar, and $0.45,1.05$, and 1.8 per cent. for Japan agar. To obtain similar consistencies Japan agar was used in higher concentrations than Bacto agar. The results were similar with the two types of agar and no differences were observed between the low and high concentrations.

(c) Finally, an experiment with five gonococcus strains showed that Stuart's medium with $1 \cdot 5$ per cent. selected Japan agar dispensed into tubes with paraffinated cottonwool or rubber plugs gave just as good results as those obtained by the original method. There was a tendency to

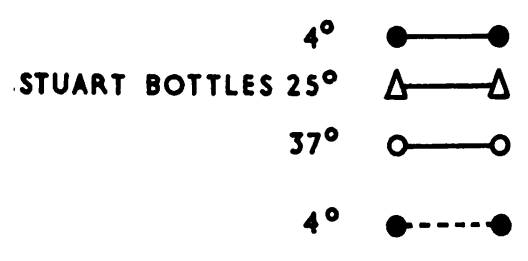

MCLEOD TUBES $25^{\circ} \quad \triangle \cdots \cdots-\Delta$

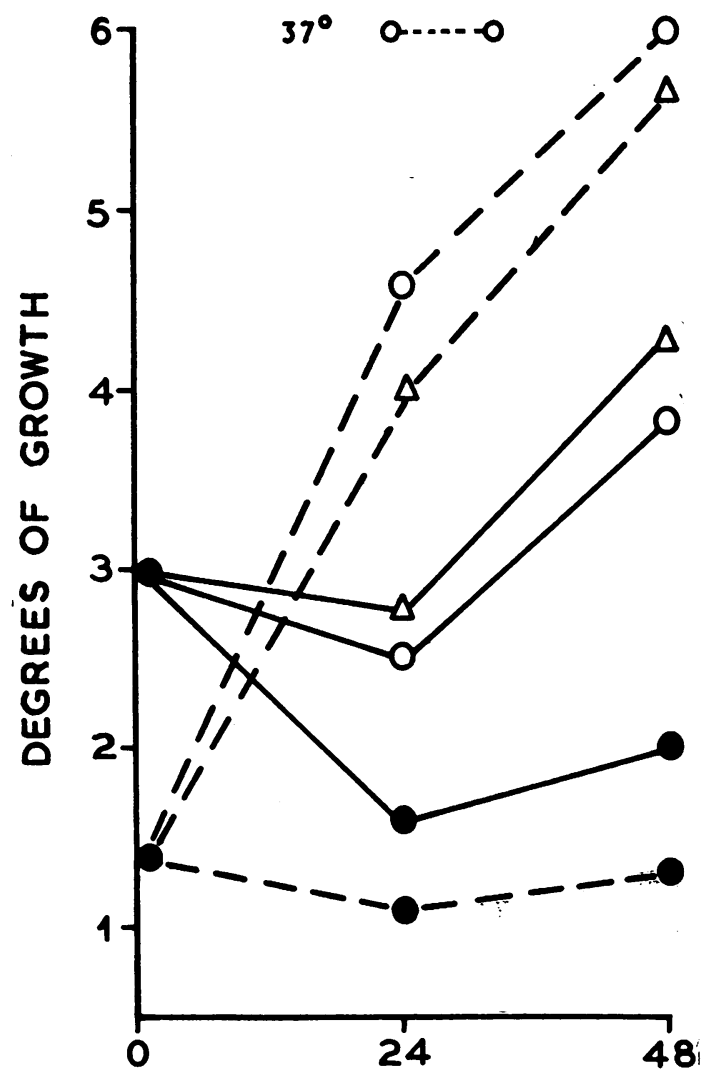

HOURS

FIG. 2.-Average degrees of growth for six artificially contaminated specimens without gonococci transported in Stuart bottles and in McLeod tubes.

better survival in the tubes in which the highest amount of medium was used.

\section{Clinical Specimens}

Preliminary Experiments with Different Swabs.-The significance of the swab type was studied in a preliminary series of duplicate specimens taken at the same time from patients attending a clinic for free treatment of venereal 
diseases. ${ }^{*}$ Three types of swabs were compared; they were prepared with hydrophobic cotton wool, hydrophilic cotton wool, and hydrophilic cotton wool + charcoal. The specimens were transported in McLeod tubes.

The swabs were compared two by two; at one time one type was used as Swab 1, another as Swab 2, and so on. Altogether 203 duplicate specimens from 151 patients ( 97 males and 54 females) were received. At the laboratory they were plated immediately on McLeod-Reymann plates, and incubated at $36^{\circ} \mathrm{C}$. in a 10 per cent. $\mathrm{CO}_{2}$ atmosphere for $24 \mathrm{hrs}$ and without $\mathrm{CO}_{2}$ for another 24 hrs. After plating, the swabs were re-inserted into the McLeod tubes and kept at room temperature $\left(23-25^{\circ} \mathrm{C}\right.$.) for $24 \mathrm{hrs}$; delayed cultures were obtained from these re-inserted swabs. The results were read after 24 and 48 hours' incubation and the degree of growth was recorded quantitatively for both the gonococci and the contaminants; 86 of the 97 specimens from the male urethra ( 89 per cent.), 23 of the 54 specimens from the female urethra (43 per cent.), and 32 of the 52 specimens from the cervix ( 62 per cent.) were positive. $\dagger$

The results of the experiments are not reported in detail, but they support the conclusions that:

(1) Swab 1 tended to give a heavier growth of gonococci and more positive cultures than swab 2;

(2) The charcoal swabs were slightly superior to those prepared without charcoal.

Comparison of the McLeod and Stuart Transportation Methods.-The material was obtained from the same clinic. When it was noticed that the swab taken first would tend to give a better growth of gonococci, it was planned to let the sequence of the swabs alternate; in this way a selective influence of seasonal variation in the specimens might be counteracted as well as other factors

* Our thanks are due to Dr. Marie Plesner, Dr. Tage Jensen, Dr. Hannes Finsen, and Dr. Arne Reyn, all of the Municipal Clinic, Nørrebrogade $18 \mathrm{~A}$, Copenhagen.

$t$ These figures include only the results read after 48 hours for the swab with hydrophobic cotton wool, plated immediately. such as source of material. Special wooden racks constructed for the alternating arrangement of the bottles and tubes were sent to the clinic accompanied by instruction forms. The duplicate specimens were collected in Stuart bottles and in McLeod tubes using charcoal swabs for both methods; the Stuart bottles and the McLeod tubes were marked 1 and 2 at the clinic, so that it was possible to study the relation between the results and the sequence of the swabs. The patients were not selected, because it appeared desirable to obtain a "random sample" of venereal patients as to sex, stage of disease, and treatment.

Plates were inoculated immediately upon arrival at the laboratory and again 24 hrs later, the swabs being replaced into the tubes or bottles and allowed to stand at room temperature between the first and second platings.

Altogether 229 duplicate cultures (458) from 156 patients (84 males and 72 females) $\ddagger$ were set up. Five were discarded because of lack of information as to numeration of the swabs, etc. Of the 81 male urethra specimens 57 ( 70 per cent.), of the 72 female urethra specimens 23 ( 32 per cent.), and of the 71 cervix specimens 34 (48 per cent.) were positive by the McLeod method plated immediately and after 48 hrs. 238 cultures were positive after immediate plating and 114 after delayed plating.

100 duplicate specimens ( 2 male and 98 female) reached the laboratory within 3 hours of being taken, 55 (49 male and 6 female) came in after 3 to 6 hours, and 69 (30 male and 39 female) came in after more than 6 hours. Thus, the distribution with respect to transportation time was fairly even; though the sex distribution was very uneven, only 2 male specimens reaching the laboratory within 3 hours as compared with 98 female specimens.

Table I shows that the numbers of specimens with Swab 1 for each method were fairly equal: 104 for McLeod and 120 for Stuart. The total numbers of specimens from the male urethra, the female urethra, and the cervix were also fairly equal: 81,72 , and 71 respectively.

$\ddagger$ As a rule, specimens were received from both urethra and cervix.

\section{TABLE I}

DISTRIBUTION OF 224 DUPLICATE CLINICAL SPECIMENS, SHOWING TRANSPORTATION TIME, SWAB NUMBER, METHOD, AND SOURCE OF MATERIAL

\begin{tabular}{|c|c|c|c|c|c|c|c|c|c|c|c|c|}
\hline \multicolumn{2}{|c|}{ Transportation Time } & $\cdots$ & $\cdots$ & \multicolumn{3}{|c|}{$\begin{array}{l}\text { "Immediate" Plating } \\
\text { Less than } 3 \text { hours after Sampling }\end{array}$} & \multicolumn{3}{|c|}{$\begin{array}{l}\text { "Immediate" Plating } \\
\text { More than } 3 \text { but Less than } \\
6 \text { hours after Sampling }\end{array}$} & \multicolumn{3}{|c|}{$\begin{array}{l}\text { "Immediate" Plating } \\
\text { More than } 6 \text { hours after Sampling }\end{array}$} \\
\hline Swab No. & .. & $\cdots$ & . & - 1 & 1 & \multirow{2}{*}{ Total } & 1 & 1 & \multirow{2}{*}{ Total } & 1 & 1 & \multirow{2}{*}{ Total } \\
\hline Method & . & . & . & McLeod & Stuart & & McLeod & Stuart & & McLeod & Stuart & \\
\hline \multirow{3}{*}{$\begin{array}{l}\text { Source } \\
\text { of } \\
\text { Material }\end{array}$} & \multicolumn{2}{|c|}{ Male Urethra } & . & $1 / 33$ & $1 / 48$ & $2 / 81$ & $21 / 33$ & $28 / 48$ & $49 / 81$ & $11 / 33$ & $19 / 48$ & $30 / 81$ \\
\hline & \multicolumn{3}{|c|}{ Female Urethra. . } & $14 / 16$ & $36 / 57$ & $50 / 73$ & $0 / 16$ & $3 / 57$ & $3 / 73$ & $2 / 16$ & $18 / 57$ & $20 / 73$ \\
\hline & Cervix & .. & $\ldots$ & $35 / 55$ & $13 / 15$ & $48 / 70$ & $3 / 55$ & $0 / 15$ & $3 / 70$ & $17 / 55$ & $2 / 15$ & $19 / 70$ \\
\hline Total & . & . & . & $50 / 104$ & $50 / 120$ & $100 / 224$ & $24 / 104$ & $31 / 120$ & $55 / 224$ & $30 / 104$ & $39 / 120$ & $69 / 224$ \\
\hline
\end{tabular}

Note: The first figure of each pair of figures refers of the number of specimens used under each of the various headings. The second figure refers to the total number of specimens from each of the three sources tested with the various time limits and methods. 
However, the distribution of Swabs 1 and 2 was not equal for these three categories. There was a relatively high number of specimens for which the McLeod method had Swab 1 from cervix and Swab 2 from urethra (55/71), while with the Stuart method only 15 of 72 specimens had Swab 1 from urethra, etc. The fact that the swab number, the method, and the source of the material were confounded made it difficult to test the significance of the different factors which might influence the results. The transportation time was also confounded with the source of specimens: only two male specimens out of 81 were received less than 3 hours after they were taken, whereas 50 and 48 out of the 72 urethra and 71 cervix specimens were received less than 3 hours after they were taken.

The incidence of positive cultures was equal in the two "swab-groups"; by the McLeod method 53 per cent. $(55 / 104)$ of the specimens with Swab 1 and 49 per cent. (59/120) with Swab 2 were positive when plated immediately, and 21 per cent. (22/104) and 22 per cent. $(27 / 120)$ when the plating was delayed. The corresponding figures for the Stuart method were 54 per cent. $(64 / 120)$ and 58 per cent. $(60 / 104)$ positive for immediate plating. and 32 per cent. (33/104) and 27 per cent. (32/120) for delayed plating.

The cultures were examined after 24 and 48 hours' growth and the results were recorded quantitatively for both the gonococci and the contaminating bacteria.

Table II shows the results for the 224 specimens. It is evident that more positive cultures were found with the Stuart method than with the McLeod method: $75: 73$, and $124: 114$ for the immediate cultures, and $51: 44$, and $65: 49$ for the delayed cultures. The number of overgrown cultures showed the opposite trend. This was most pronounced for the delayed cultures read after 48 hours, 84 overgrown cultures being found with the McLeod method against 54 with the Stuart method. The cultures were mainly overgrown by $B$. proteus, E. coli, staphylococci, and diptheroids. The delayed platings gave an average loss in positive cultures (read after $48 \mathrm{hrs}$. incubation) of 48 per cent. $(59 / 124)$ by the Stuart method, and 57 per cent. (65/114) by the McLeod method. Of the 114 specimens which were positive after immediate plating by both methods, 27 gave positive results after delayed plating by only one of the methods; of these the Stuart method gave positive results in twenty specimens and the McLeod method in seven specimens only. This difference is statistically significant. Three of the ten specimens in which the Stuart method gave positive and the McLeod method negative results (after immediate plating) were still positive by the Stuart method after delayed plating, two being negative, and five overgrown. Thus, after delayed plating, the Stuart method "preserved" the positive results better than the McLeod method.

Table III (opposite) shows that, for the immediate cultures, the overall degree of contamination was about the same by the two methods; for the delayed cultures the number of contaminated plates was higher by the Stuart than by the McLeod method, but as already mentioned the number of completely overgrown plates was higher by the McLeod method. Plates without contamination (positive and negative cultures) were more frequent by the Stuart than by the McLeod method.

The $48 \mathrm{hrs}$ readings gave the highest numbers of positive cultures; in the further descriptions of the results only these readings are used. This involves the loss of three positive cultures with the McLeod method and one with the Stuart method; after 48 hours these cultures were overgrown with contaminants. The results were made up both quantitatively and qualitatively.

Immediate Plating.-In ten cases the Stuart method gave positive gonococcus cultures where the McLeod method gave negative cultures, and the degree of growth was greater with the Stuart method in 29 cases. No cases were found in which the McLeod method gave positive results and the Stuart method negative results; only in sixteen cases was a heavier growth obtained with the Mcleod method than with the Stuart method (Table IV, opposite).

\section{TABLE II}

DISTRIBUTION OF 224 DUPLICATE CULTURES (IMMEDIATE AND DELAYED), SHOWING QUANTITATIVE RESULTS FOR GROWTH OF GONOCOCCI AND NUMBER OF OVERGROWN PLATES AT 24 AND 48-hr READINGS

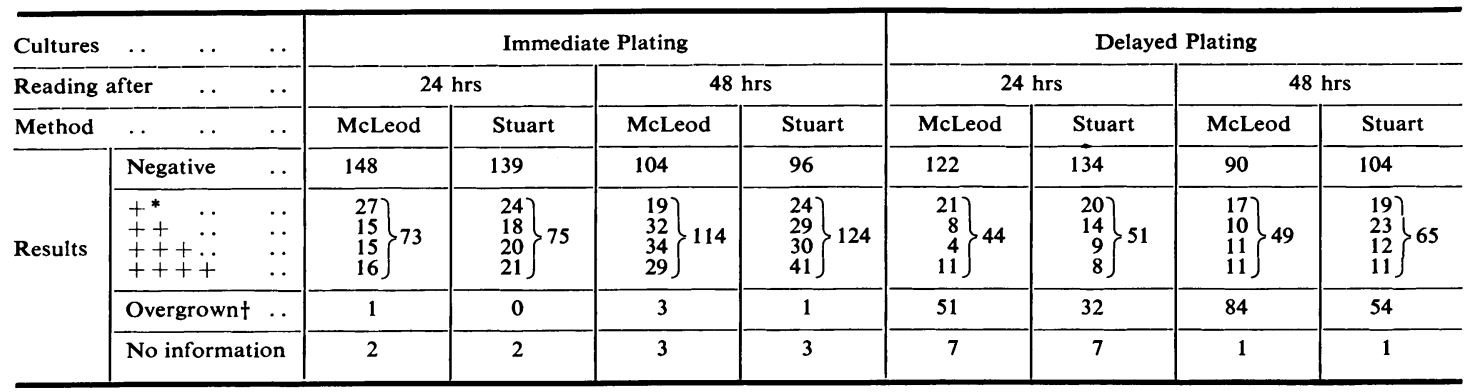

$*+\ldots++++$ : Increasing degrees of growth of gonococci.

+ Overgrown: Inoculated areas completely covered with contaminants, mainly $E$. coli or proteus. 
TABLE III

DISTRIBUTION OF 224 DUPLICATE CULTURES (IMMEDIATE AND DELAYED) DEGREE OF CONTAMINATION-24 AND 48-hr READINGS

\begin{tabular}{|c|c|c|c|c|c|c|c|c|c|c|c|}
\hline \multirow{2}{*}{\multicolumn{2}{|c|}{$\frac{\text { Cultures }}{\text { Reading after }}$}} & \multirow{2}{*}{ 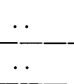 } & \multirow{2}{*}{$\cdots$} & \multicolumn{4}{|c|}{ Immediate Plating } & \multicolumn{4}{|c|}{ Delayed Plating } \\
\hline & & & & \multicolumn{2}{|c|}{$24 \mathrm{hrs}$} & \multicolumn{2}{|c|}{$48 \mathrm{hrs}$} & \multicolumn{2}{|c|}{$24 \mathrm{hrs}$} & \multicolumn{2}{|c|}{$48 \mathrm{hrs}$} \\
\hline Method & . & $\ldots$ & . & McLeod & Stuart & McLeod & Stuart & McLeod & St:uart & McLeod & Stuart \\
\hline \multirow{4}{*}{ Results } & \multicolumn{3}{|c|}{$\begin{array}{c}\text { No Contamina- } \\
\text { tion .. }\end{array}$} & 92 & 91 & 23 & 27 & 16 & 26 & 8 & 12 \\
\hline & $\begin{array}{l}+* \\
++ \\
+t \\
+\end{array}$ & $\begin{array}{l}\cdots \\
\cdots \\
-\end{array}$ & $\begin{array}{l}\ldots \\
\ldots \\
\ldots\end{array}$ & $\left.\begin{array}{c}63 \\
29 \\
30 \\
9\end{array}\right\} 131$ & $\left.\begin{array}{l}57 \\
31 \\
34 \\
11\end{array}\right\} 133$ & $\left.\begin{array}{l}75 \\
53 \\
38 \\
29\end{array}\right\} 195$ & $\left.\begin{array}{l}66 \\
47 \\
52 \\
27\end{array}\right\} 196$ & $\left.\begin{array}{l}12 \\
23 \\
47 \\
68\end{array}\right\} 150$ & $\left.\begin{array}{l}44 \\
27 \\
53 \\
45\end{array}\right\} 169$ & $\left.\begin{array}{l}9 \\
17 \\
33 \\
72\end{array}\right\} 141$ & $\left.\begin{array}{l}26 \\
27 \\
39 \\
65\end{array}\right\} 157$ \\
\hline & Ove & rownt & . & 1 & 0 & 3 & 2 & 51 & 32 & 84 & 54 \\
\hline & No & formati & ion & 0 & 0 & 3 & 3 & 7 & 7 & 1 & 1 \\
\hline
\end{tabular}

$*+\ldots++++$ : Increasing degrees of growth.

t Overgrown: Inoculated area completely covered with contaminants, mainly E. coli or proteus.

TABLE IV

DISTRIBUTION OF 113 CASES WITH DISCREPANT RESULTS BY THE STUART AND MCLEOD METHODS, OUT OF 448 TESTS OF 224 DUPLICATE CLINICAL SPECIMENS

\begin{tabular}{|c|c|c|c|}
\hline \multirow{2}{*}{ Discrepancy } & \multicolumn{2}{|c|}{ Number of Cultures } & \multirow{2}{*}{ Total } \\
\hline & $\underset{\text { Plating }}{\text { Immediate }}$ & $\begin{array}{l}\text { Delayed } \\
\text { Plating }\end{array}$ & \\
\hline $\begin{array}{l}\text { Stuart positive, McLeod nega- } \\
\text { tive } \ldots \\
\text { Stuart positive }\end{array}$ & $\begin{array}{l}10 \\
29\end{array}$ & $\begin{array}{l}23 \\
16\end{array}$ & \multirow[t]{2}{*}{$\left.{ }^{33}\right\}_{11}$} \\
\hline $\begin{array}{l}\text { McLeod positive stronger than } \\
\text { Stuart positive, Stuart nega- } \\
\text { McLeod posive, } \\
\text { tive }\end{array}$ & $\begin{array}{r}16 \\
0\end{array}$ & $\begin{array}{r}12 \\
7\end{array}$ & \\
\hline None $\ldots$ & 169 & 166 & 335 \\
\hline$\ldots \quad \ldots$ & 224 & 224 & 448 \\
\hline
\end{tabular}

As a general rule, the number of positive cultures was equal for Swabs 1 and 2, but in 22 cases in which Swab 1 was used in the Stuart method the degree of gonococcus growth was greater with the Stuart method than with the McLeod method; the opposite occurred in four cases only. When Swab 2 was used in the Stuart method a heavier growth was obtained in seven cases, whereas the McLeod method gave a heavier growth in twelve cases.

Delayed Plating.-The tendency was similar to that seen after immediate plating; in 23 cases the Stuart method gave positive cultures where the McLeod method gave negative cultures, and in sixteen cases the growth was heavier with the Stuart method. In seven cases positive with the McLeod method, the Stuart method gave negative results, and in twelve cases the growth was heavier with the McLeod method. The numbers of positive cultures were about equal for Swabs 1 and 2, but when Swab 1 was used in the Stuart method the growth was heavier than for the McLeod method in thirteen cases, and the opposite occurred in only five cases. When Swab 2 was used with the Stuart method the corresponding figures were three and seven respectively (Table IV).

The supposed superiority of the Stuart method already seen in Table II was thus demonstrated both qualitatively and quantitatively, but the tendency to better results with Swab 1 could be demonstrated in this material only when the degree of growth was taken into consideration.

The quantitative readings of the degree of contamination showed for the immediate cultures that more strongly positive readings were found with the Stuart method than with the McLeod method; two overgrown cultures were found with this method and three with the McLeod method.

For the delayed cultures the "same" number of strongly contaminated readings was observed with the two methods, but 84 overgrown cultures were found with the McLeod method against 54 with the Stuart method (Table III).

Results obtained after the Introduction of a Modified Stuart Method in the Routine.-When it was observed that the agar concentration might be increased to about 1.5 per cent. without any damaging influence, it was decided to introduce the Stuart method into the routine. For this purpose the medium was dispensed in $10-\mathrm{ml}$. amounts and $15 \times 150 \mathrm{~mm}$. tubes were used instead of bottles. It had also been shown in control experiments that tubes in which the medium was blue gave less survival than did the McLeod tubes. Therefore, it was stressed to the users that the tubes with blue medium were completely useless, and that to avoid the irreversible discoloration of the methylene blue the tubes should be protected from light.

In July, 1959, the modified Stuart method was gradually introduced and for 3 weeks the two methods were used side by side. Of altogether 6,499 specimens received from 26 July to 16 August, 3,023 were transported in McLeod tubes and 3,476 in Stuart tubes; it was assumed that the two corresponding sets of specimens did not differ qualitatively to any large degree (Table V, overleaf).

Of the total number of cultures (overgrown included) 12.4 per cent. of those transported in the Stuart tubes were positive, but only $8 \cdot 5$ per cent. of those transported in the McLeod tubes. The proportion of overgrown cultures showed the opposite tendency: $9 \cdot 0$ per cent. were 


\section{TABLE V}

COMPARISON BETWEEN RESULTS OF TRANSPORTATION IN MCLEOD AND STUART TUBES FOR THE PERIOD 26 JULY TO 19 AUGUST, 1959

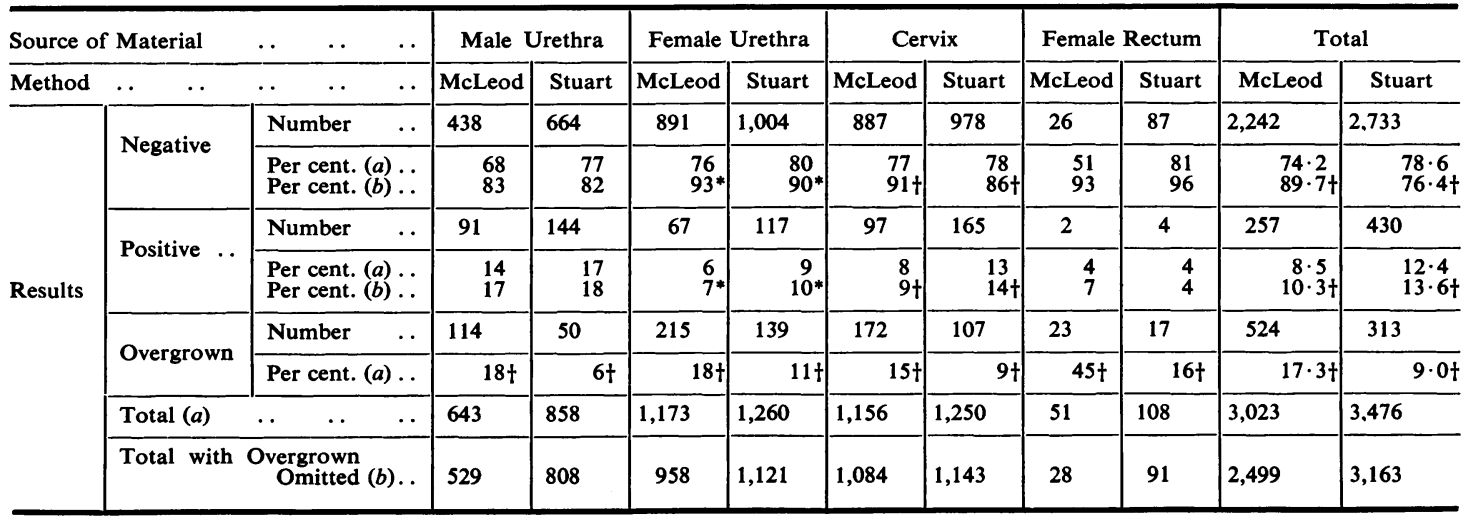

observed from Stuart tubes against $17 \cdot 3$ per cent. from McLeod tubes; this difference is statistically significant $(P<0 \cdot 1$ per cent.).

$4 \cdot 6$ per cent. overgrown cultures were found among specimens which had reached the laboratory $\leqslant 16$ hours after sampling; 22.6 per cent. overgrown cultures were found among specimens transported for 24 hours or more. In the latter category the Stuart method gave nearly twice as many positive and half as many overgrown cultures as the McLeod method: $9.6 \sim 5.7$ per cent. and $17.4 \sim 32.3$ per cent. The difference was somewhat less for specimens transported for $\leqslant 16$ hours: $15.0 \sim 11.3$ per cent. and $3.4 \sim 5.9$ per cent.

The incidence of positive cultures in the two series was evaluated, omitting the overgrown cultures. For the Stuart tubes the yield of positive cultures was 13.6 per cent. and for the McLeod tubes $10 \cdot 3$ per cent.; this difference is also statistically significant $(P<0 \cdot 1$ per cent.).

For the male specimens alone it was possible to demonstrate a significant difference only in the number of overgrown cultures; the same applied to the female specimens from the rectum. For the specimens from the female urethra and the cervix, the Stuart method gave more positive cultures and a lower number of overgrown cultures, the difference in both cases being statistically significant $(P<0 \cdot 1$ per cent.).

During the experimental period the incidence of overgrown cultures was extraordinarily high, since usually only about 3 per cent. give overgrown cultures.

Use of Polymyxin B Sulphate.-215 female specimens from various sources with a known high incidence of positive cultures were plated on McLeod-ascitic plates with and without the addition of Polymyxin $B$ in a concentration of $5 \mu \mathrm{g} . / \mathrm{ml}$. (36 units $/ \mathrm{ml}$.), 3.6 times the concentration used by Stuart and Crookes (1959). The swabs were alternately used (in series of five) first on one type and then on the other type of plates. The degrees of growth were registered for $N$. gonorrhoeae, E. coli, and "other bacteria". Also some notes were taken on the growth of colonies discolouring the heated blood of the medium. These colonies comprised mainly diphtheroids, or other undefined Gram-positive rods, the growth of which altered the colour of the medium from brown to yellow or green.

Altogether 52 gonococcus cultures were obtained on the ordinary plates and 51 on the Polymyxin plates, the only discrepant result being one culture which was negative on the Polymyxin plate and positive on the ordinary plate. The colonies of $N$. gonorrhoeae were of equal size on the two types of plate, and the degree of growth was, with the exception of two cultures, equal to or slightly better on the Polymyxin plates than on the routine plates.

A heavy growth of $E$. coli was observed on 64 routine plates, but no Polymyxin plates showed any growth of these organisms; however, a tendency to heavier contaminations was seen with other bacteria, mainly Grampositive rods. A heavy growth of diphtheroids was found on 31 routine plates and forty Polymyxin plates respectively. The above-mentioned gonococcus culture which was not recovered from the Polymyxin plate was overgrown by diphtheroids.

\section{Discussion}

Two methods of transporting gonococcus material have been compared: the so-called "McLeod method" which is used routinely at the Statens Seruminstitut in Copenhagen (Reyn, 1951) and Stuart's method (Stuart, 1946; Moffett and others, 1948; Stuart and others, 1954; Stuart, 1956; Crookes and Stuart, 1959; Stuart, 1959; Stuart and Crookes, 1959). For the comparison both artificial and clinical 
specimens were used and experiments were carried out simultaneously with both types. The artificial specimens were prepared from recently isolated, pure gonococcus cultures and from some of the most frequent contaminants. $B$. proteus was tested in a separate experiment. Two sets of duplicate clinical specimens were obtained from a clinic for the free treatment of venereal diseases. The first set included 203 duplicate specimens from 151 patients $(97$ males and 54 females) and the second set included 224 duplicate specimens from 153 patients ( 81 males and 72 females). The results were estimated quantitatively, both for the gonococcus cultures and for the contaminants.

Three types of wooden applicators were compared:

(1) ordinary hydrophilic,

(2) hydrophobic;

(3) hydrophilic cotton-wool swabs impregnated with charcoal (Moffett and others, 1948).

They were all boiled in buffer. Both artificial and clinical specimens (first set) were used for the comparison. In Stuart's medium the charcoal swabs were highly superior to the two others, but no significant difference was seen when the charcoal swabs were used in McLeod's medium. The two other swabs gave about equal results. Similar results were obtained by Cooper (1957) and by Ringertz (1960). Thus, we have an explanation for our finding in 1947 (Reyn, 1949, 1951), that the McLeod method gave results equal to those obtained for the Stuart method. At that time unboiled, hydrophobic cotton-wool applicators were used for both methods.

The effect of the transportation time was studied in ten artificial, pure gonococcus specimens "transported" at room temperature for 24,48 , and 72 hours. With time all the specimens showed a gradual decrease in growth, but the degree of growth was always greater for the Stuart method than for the McLeod method. After $72 \mathrm{hrs}$ ' transportation, only four cultures were positive with the McLeod method against nine with the Stuart method.

The results obtained with clinical specimens (second set) also showed that the Stuart method preserved the gonococci for a longer time than the McLeod method. Details of these results are given below.

The effect of temperature (and time) was studied in artificially contaminated specimens; it was found that the Stuart method preserved the gonococci better and showed less growth of contaminants than the McLeod method. At $4^{\circ} \mathrm{C}$ the initial growth of contaminants tended to be higher with the Stuart method than with the McLeod method, but after storage at this temperature for 24 hours a drop in growth was noted. This was followed by an insignificant rise after 48 hours. The McLeod method gave constant low growth after 24 and 48 hours as compared with the initial growth.

At $25^{\circ}$ and $37^{\circ} \mathrm{C}$. the degree of growth was fairly constant for the Stuart method after 24 hours, whereas the McLeod method showed a definite rise. After 48 hours there was a distinct rise for both methods, but the growth was less heavy for the Stuart method than for the McLeod method. The growth of $B$. proteus was abundant in both methods, even at $4^{\circ} \mathrm{C}$.

With the first set of clinical specimens which were used to compare the different types of swab, a tendency to higher incidence of positive cultures and heavier growth was found for the swab taken first (Swab 1).

Hence, in the main experiment with clinical specimens, it was decided to alternate the sequence of the swabs. Our plan was successful as to the number of specimens with each swab category: 104 specimens had Swab 1 transported in McLeod tubes and 120 specimens had Swab 1 transported in Stuart bottles and vice versa.

The material in the first set of clinical specimens was somewhat selected; the male specimens prevailed and duplicate specimens were taken only when it was highly probable that they would be positive. This resulted in a higher percentage of positive cultures in the first than in the second set.

From the beginning we did not expect to find a distinct difference between the two methods, and in order to be able to analyse as many relevant factors as possible it was decided to aim at a "random sample" of specimens from venereal patients; in this way a mixture of chronic and acute cases would be obtained, some treated and some untreated. Information was collected on the transportation time because it was thought possible that the difference between the methods could be demonstrated only in specimens transported for a longer time. The specimens reached the laboratory within 2 to 9 hours of being taken. They were plated immediately upon arrival and the swabs were re-inserted into the tubes or bottles and kept at room temperature $\left(23-25^{\circ} \mathrm{C}\right.$.) for 24 hours; after this delay they were plated again. The procedure involved a spreading of the contamination on the swab and may account for the rather great loss in positive cultures from immediate to delayed plating, 57 per cent. $(65 / 114)$ for the McLeod and 48 per cent. $(59 / 124)$ for the Stuart method.

When the results were analysed it appeared that the swab number, the method, the source of material (female or male), and the transportation time were highly confounded. Only a few sub-groups contained sufficient numbers to analyse the significance 
of the factors believed to be relevant. Clinical information about diagnosis, treatment, or microscopy was not collected.

However, an analysis in detail was not found to be as important as primarily thought, since it was evident that the Stuart method was distinctly better than the other method irrespective of swab number, source of material, and transportation time. More positive cultures were found, and the loss in positive cultures and the number of overgrown cultures after delayed plating were less.

After immediate plating, ten positive cultures were found with the Stuart method and none with the McLeod method. After delayed plating 23 positive cultures were found with the Stuart method which were negative with the McLeod method, and seven negative with the Stuart method which were positive with the McLeod method.

The superiority of the Stuart method was also indicated by the results of the quantitative readings.

After delayed plating the degree of contamination and the number of overgrown cultures were greater with the McLeod method (84) than with the Stuart method (54). The overgrowth was mainly due to $E$. coli, B. proteus, staphylococci, and diphtheroids. The positive results found after immediate plating were also significantly better "preserved" by the Stuart method.

The superiority of the Stuart method was also shown by a series of routine results obtained after it had been gradually introduced. The yield of positive cultures in 6,499 specimens was significantly higher by this method and the number of overgrown cultures was significantly lower. Furthermore, the recent observation by Stuart and collaborators that the addition of Polymyxin B sulphate to the culture medium inhibits the growth of $E$. coli without affecting the growth of $N$. gonorrhoeae was confirmed. However, the inhibition of $E$. coli was obtained at the expense of a somewhat heavier contamination with other bacteria, especially diphtheroids and other Gram-negative rods, and it was also found that the addition of Polymyxin to the transportation medium was not very useful.

Beyond doubt, Stuart's non-nutrient medium is very convenient for the transportation of gonococcus material. It allows the culturing of gonococci in artificial specimens of an average degree of positivity after 72 hrs' "transportation" at room temperature, and the usual contaminants (except $B$. proteus) do not develop in this medium as readily as in a nutrient medium such as that of McLeod. The thioglycollate content obviates the addition of $\mathrm{CO}_{2}$. Penicillin is destroyed by reducing substances, and thioglycollate may, also in this respect, be advantageous. The minimal concentration of methylene blue apparently has no inhibitory influence.

In addition, the medium is suitable for the transportation of $T$. vaginalis and bacteria other than gonococci (Cooper, 1957; Stuart, 1956; Stuart, 1959); this is very practical, especially for small laboratories. The semi-fluid character of the original medium and its dispensing in screw-capped bottles are somewhat inconvenient. However, in the present study, it was found that the agar concentration could be increased to at least 1.5 per cent. without affecting the results. The medium could also be dispensed in $10-\mathrm{ml}$. amounts in $15 \times 150 \mathrm{~mm}$. tubes, with either paraffinated cotton wool or rubber stoppers and was still superior to the McLeod medium dispensed in the same way.

\section{Summary}

Factors affecting the survival and growth of the gonococcus are discussed and transportation methods are described with special reference to that suggested by Stuart (1946) and improved by Moffett, Young, and Stuart (1948).

Evidence has been accumulating during the last decade that Stuart's method is superior to any of those commonly used hitherto, but very few direct comparisons of this with other methods have been reported. The present work compares Stuart's method with that used at the Statens Seruminstitut in Copenhagen. The Danish transportation medium consists of McLeod's chocolate agar. The two methods have been compared using both artificial and clinical specimens, and the results have been estimated quantitatively, with respect to both gonococci and contaminants. Different types of applicators were compared; when used in Stuart's medium applicators impregnated with charcoal were highly superior to other types of swabs. No significant difference was demonstrated when the charcoal swabs were used in McLeod's medium.

The effect of temperature and time was especially studied in artificially-contaminated specimens. The Stuart method preserved the gonococci better and showed less growth of the contaminants than the McLeod method; the growth of $B$. proteus was abundant by both methods. 
With the clinical specimens ("immediate" and "delayed" plating) the Stuart method was distinctly better than the McLeod method irrespective of source of material and transportation time.

The observation by Stuart and Crookes (1959) that the addition of Polymyxin B sulphate to the culture medium inhibits the growth of $E$. coli without influencing the growth of $N$. gonorrhoeae was confirmed. The inhibition of E. coli. was obtained at the expense of a more heavy contamination with diphtheroids and other Gram-negative rods.

The semi-fluid character of the original medium and its dispensation in screw-capped bottles is somewhat inconvenient; the present study showed that the agar concentration could be increased to about 1.5 per cent. without any influence on the results. The medium could also be dispensed in $15 \times 150 \mathrm{~mm}$. tubes with tight stoppers.

The result of the gradual introduction of the Stuart method in July, 1959, was that 12.4 per cent. positive cultures were found after transportation in Stuart tubes and 8.5 per cent. after transportation in McLeod tubes; the proportion of overgrown cultures showed the opposite tendency.

\section{REFERENCES}

Alexander, J. G. (1952). J. Obstet. Gynaec. Brit. Emp., 59, 246. Barlow, J. L., Yamakawa. Y. and Cavanaugh, D. C. (1955). Jap. J. med. Sci. Biol., 8, 171 .

Beakley, J. W. (1957). Publ. Hlth Lab., 15, 11

Buck, T. C, Jr. (1947). J. vener. Dis. Inform., 28, 6.

Burrows, W. (1954). "Textbook of Microbiology", 16th ed. Saunders, Philadelphia.

Colquhoun, C. B. G., and Cooper, G. N. (1957). Med. J. Aust., 1, 413.

Cooper, G. N. (1957). J. clin. Path., 10, 226.

Cox, O. F., McDermott, M. V. (1943). Amer. J. publ. Hlth, 33, 149.

Crookes, E. M. L., and Stuart, R. D. (1959). J. Path. Bact., 78, 283.

Deakin, R. (1942). Amer. J. Syph., 26, 313.

Gould, R. G., Kane, L. W., and Mueller, J. H. (1944). J. Bact., 47, 287.

Griffin, P. J., and Rieder, S. V. (1957). Yale J. Biol. Med., 29, 613.

Heidbreider, G. A., Laurence, C. A., Deboynton, E., and Lahr, w. (1955). "Symposium on Recent Advances in the Study of Venereal Disease." April 28 and 29, 1955.

Hill, J. H., Nell, E. E., and Mueller, A. M. (1948). In "Recent Advances in the Study of Venereal Diseases: A Symposium", p. 146. Venereal Disease Education Institute and U.S. Public Health Services, Washington.

Hirschberg, N. (1945). Amer. J. Syph., 29, 64.

Hüllstrung, H. (1949). Derm. Wschr., 120, 33

Hällstrung, H. (1949). Derm. Wschr..192, 33.

Lankford, C. E., Scott, V., Cox, M. F., and Cooke, W. R. (1943). J. Bact., 45, 321.

- and Skaggs, P. K. (1946). Arch. Biochem., 9, 265.

Laurell, A. B. Personal communication 1959.

LeMinor, L., Le Minor, S., and Combes, R. (1949). Ann. Inst. Pasteur, $77,327$.

Ley, H. L., and Mueller, J. H. (1946). J. Bact., 52, 453.

McLeod, J. W., Coates, J. C., Happold, F. C., Priestley, D. P., and Wheatley, B. (1934). J. Path. Bact., 39, 221

McLeod, J. W. (1947). Brit. J. vener. Dis., 23, 53.

McClure, W. B., and Miller, A. M. (1946). Canad. J. publ. Hlth, 37, 146.

Moffet, M., Young, J. L., and Stuart, R. D. (1948). Brit. med. J.,

Mullaney, P. J. (1951). J. Irish med. Ass., 29, 145

Mülhens, K. (1950). Arch. Derm. Syph. (Berl.), 191, 680.

Peizer, L. R. (1942). J. Bact., 43, 733.

— and Steffen, G. I. (1943). J. Lab. clin. Med.

- —, and Klein, S. (1949). Publ. Hlth Rep. (Wash.), 64, 599.
Porterfield, J. D., and Nelson, E. A. (1944). Amer. J. Syph., 28, 417. Rahn, O. (1945). Bact. Rev., 9, 1.

Reymann, F. (1941). Thesis. Munksgaard, Copenhagen.

Reymann, F. (1944). Acta derm.-venereol. (Stockh.), 24, 130.

Reyn, A. (1947a). Thesis, Munksgaard, Copenhagen. (1947b). Unpublished observations.

(1950). Forhandlinger Nordisk Dermatologisk Forenings, 1949, 12te Møte, Oslo, pp. 51-62. Håkon Ohlssons Boktryckeri, Lund. (1951). Acta. derm.-venereol. (Stockh.), 31, 34.

Ringertz, O. (1960). Acta path. microbiol. scand., 48, 105.

Ringertz, O. (1960). Acta path. microbiol. Scand, 48, 105.

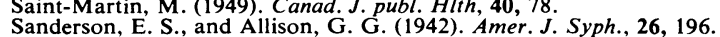

Schubert, J. H., Bucca, M. A., and Thayer, J. D. (1947). J. vener. Dis. Inform., 28, 214.

Stokinger H. E. Acherman, H., and Carpenter, C. M. (1943). J. Bact., 45, 31 .

Stuart, R. D. (1946). Glasg. med. J., 27, 131

(1956). Canad. J. publ. Hlth, 47, 114.

(1959). Publ. Hlth Rep. (Wash.), 74, 431

, and Crookes, E. M. L. (1959). Publ. Hith Lab., 17, 41.

, Toshach S. R. and Patsula, T. M. (1954). Canad.J. publ. Hlth, $45,73$.

Sulkin, S. E., and Willett, J. C. (1944). Vener. Dis. Inform., 25, 138

Wilkinson, A. E. (1951). Brit. J. vener. Dis., 27, 200.

Wortman, M. S., Gronau, A., Deakin, R., and Love, F. (1941). Vener. Dis. Inform., 22, 195.

\section{Résumé}

On discute les facteurs affectant la survivance et la multiplication du gonocoque et l'on décrit les méthodes de transport des prélèvements, avec référence spéciale à celles suggérées par Stuart (1946) et améliorées par Moffett, Young, et Stuart (1948).

Pendant ces dix dernières années on a accumulé des preuves que la méthode de Stuart est supérieure à toutes autres habituellement employées jusqu'ici, mais très peu de comparaisons directes entre les méthodes ont été rapportées. Le travail présent compare la méthode de Stuart et celle employée à l'Institut Sérologique National de Copenhagen (Statens Seruminstitut). Le milieu de transport danois consiste en l'agar-chocolat de McLeod. On a comparé les deux méthodes en employant des échantillons médicaux et de laboratoire, et on a évalué quantitativement les résultats concernant aussi bien les gonocoques que les contaminants. On a comparé de différents types d'applicateurs; pour le milieu de Stuart, les applicateurs imprégnés de charbon se sont montrés hautement supérieurs aux autres instruments. On ne décéla aucune différence appréciable avec l'emploi des applicateurs au charbon sur le milieu de McLeod.

On étudia spécialement les effets de la température et du passage du temps sur des échantillons artificiellement contaminés. La méthode de Stuart preservait mieux les gonocoques et montrait moins de contaminants que celle de McLeod; des colonies de $B$. proteus abondaient avec les deux méthodes.

Avec des prélèvement médicaux (inoculations des boîtes de Petri "immédiate" et "retardée") la méthode de Stuart fut distinctement meilleure que celle de McLeod, indépendamment de l'origine du matériel et du temps de transport.

L'observation par Stuart et Crookes (1959) que l'addition de sulfate de Polymyxine B au milieu de culture inhibe la multiplication de l'E. coli sans influencer celle de $N$. gonorrhoeae fut confirmée. L'inhibition de $E$. coli fut obtenue au dépens d'une contamination plus forte avec des bacilles diphtéroïdes et autres bacilles Gramnégatifs. 
Le caractère semi-liquide de milieu original et sa répartition dans des flacons bouchés à vis est quelque peu incommode; l'étude présente montra que la concentration d'agar pourrait être augmentée à près de $1,5 \%$ sans aucune influence sur les résultats. On peut aussi distribuer le milieu dans des tubes $(15 \times 150 \mathrm{~mm}$. $)$ bien bouchés.
La conséquence de l'introduction graduelle de la méthode de Stuart en Juillet, 1959, fut que l'on trouva $12,4 \%$ de cultures positives après le transport dans des tubes de Stuart et $8,5 \%$ après le transport dans des tubes de McLeod; la proportion des cultures contaminées accusa une tendence opposée. 